\title{
“Oriundi RegNi Portugalis". Portugueses en Mallorca al Final DE LA EdAd Media
}

\author{
Maria Barceló Crespí ${ }^{1}$ \\ InÉs CALDERÓn MEDINA² \\ Universidad de las Islas Baleares
}

Recibido: 15 de diciembre de 2018

Aceptado: 20 de febrero de 2019

A Luis Adão da Fonseca.

\section{Resumen}

La conquista de Ceuta en 1415 consolidó el acceso de los portugueses al Mediterráneo, desde entonces aumentó su presencia en la isla de Mallorca. A través de la documentación notarial se analiza la presencia y actividad de los portugueses en la ciudad de Mallorca al final de la Edad Media.

\section{Palabras clave}

Portugal, Reino de Mallorca, Edad Media.

\begin{abstract}
The conquest of Ceuta in 1415 strengthened the Portuguese access to the Mediterranean, increasing their presence on the Island of Majorca since then. The presence and actions of the Portuguese in the city of Majorca, at the end of the Middle Ages are analysed through the notarial documents.
\end{abstract}

\section{Keywords}

Portugal, Kingdom of Majorca, Middle Ages.

\section{Resumo}

A conquista de Ceuta em 1415 consolidou o acesso dos portugueses ao Mediterrâneo, desde então aumentou a sua presença na ilha de Maiorca. Através da documentação notarial é analisada a presença e atividade dos portugueses na cidade de Maiorca no final da Idade Média.

\section{Palavras chave}

Portugal, Reino de Maiorca, Idade Média.

\footnotetext{
1 Dpto. Ciencias Históricas y Teoría de las Artes. Universidad de las Islas Baleares. Correo electrónico: m.barcelocrespi@uib.es. ORCID: https://orcid.org/0000-0002-6382-7908.

2 Dpto. Ciencias Históricas y Teoría de las Artes. Universidad de las Islas Baleares. Correo electrónico: ines.calderon@uib.es. ORCID: https://orcid.org/0000-0002-1274-3691.
} 
La conquista de Tarifa por parte del rey de Castilla en 1292 representó la apertura de las rutas comerciales portuguesas hacia el Mediterráneo. Desde entonces la monarquía lusa, empujada por la aristocracia y sectores de comerciantes extranjeros, principalmente italianos, impulsó este nuevo espacio en el comercio internacional, que permitía el acceso al Magreb y a la ruta que comunicaba la península italiana con Flandes ${ }^{3}$. La toma de Ceuta en 1415 fue el hito fundamental que permitió el acceso de los portugueses al Mediterráneo. La consolidación se desarrolló en el tiempo de Alfonso V con su expansión por el norte africano y la toma de Guinea, que le daba acceso al África negra; y de los archipiélagos atlánticos de Azores y Madeira. Esta expansión convirtió a los portugueses en un importante actor en el comercio mediterráneo de esclavos y azúcar ${ }^{4}$, pero también aumentó su actividad corsarias

Hasta la publicación de la obra de Luis Adão da Fonseca ${ }^{6}$, el estudio de los portugueses en el Mediterráneo había sido un tema poco explorado, opacado, tal vez, por su predominancia en la expansión transoceánica? ${ }^{7}$ Sin embargo, desde entonces, el interés por el análisis de la presencia portuguesa ha ido aumentando en todas las orillas del "Mare Nostrum". Pero a pesar de los esfuerzos, la actividad y presencia de los portugueses en el archipiélago balear es aún poco conocida.

La historiografía lusitana ha analizado la actividad de los portugueses en el Mediterráneo Occidental durante los siglos XIV y XV, incidiendo especialmente en las comunidades

\footnotetext{
FonsECA, "Portugal e o Mediterrâneo no final da Idade Média: uma visião de conjunto”, pp. 13-27, p. 17. González Arévalo establece que en 1438 Mallorca se consagra como la escala más importante de la ruta de Poniente que efectuaban las galeras venecianas y que tenía como destino Flandes, pasando por todo el litoral atlántico portugués. GonzÁlez ArÉvalo, "Acordes y desacuerdos. Navegación y comercio de las galeras mercantiles de Venecia y Florencia en el Mediterráneo ibérico desde una perspectiva comparada", pp. 156-157. LóPez de COCA CASTAÑer, "Las galeras venecianas de Poniente”, pp. 113- 172.

4 Abulafía, El gran mar. pp. 410-412. Unali, Ceuta 1415. Los orígenes de la expansión europea en África. Duarte, "Regresso a Ceuta" pp. 99-142. Idem, Ceuta 1415. Seisentos anos depois.

5 López de COCA CASTAÑer, "Granada y la expansión portuguesa en el Magreb extremo”, pp. 351-367. FÁBregas, García. "Actividad marítima y mercantil nazarí en el Magreb occidental: relatos de un observador portugués en el Estrecho" pp. 151-173.

6 Fonseca, Navegación y Corso. IDEM, Portugal entre dos mares. IDEM, "O porto nas rotas de Mediterrâneo Occidental (vésperas da Época Moderna), pp. 127-139. IDEM, "As rotas da navegação portuguesa entre o Mediterrâneo e o Atlântico na época de Colombo" pp. 517-535. Un estado de la cuestión elaborado por el autor en 2002 puede verse en IDEM, "Le Portugal et la Mediterranée au XVe siècle", pp. 3-34. En 2001 coordinó Fonseca y Cadeddu, (Coords), Portogallo Mediterráneo.

7 A pesar de que los Descubrimiento portugueses eran el campo de investigación destacado, sí se habían efectuado algunos estudios incipientes sobre la actividad de los portugueses en el Mediterráneo, como Heers, "L'expansion matitime portugaise à la fin du Moyen Age. La Mediterranée", pp. 5-33; IDEM, "Portugais et Génois au XV Siècle: La rivalité Atlantique- Méditerranée", pp. 138-147. MAdureLL Marimon, "Portugueses em Barcelona (1391-1441)", pp. 254-279. Rau, "Portugal e o Mediterrâneo". En otras obras dedicadas al comercio mediterráneo se mencionaba la presencia de mercaderes portugueses, véase, Macaire, Majorque et le commerce international, pp. 486-487. Giral-Hardziossif, Valence, port méditerranéen au XVé siécle, (1410-1525), p. 12.

8 Sobre la presencia de portugueses en Venecía, véase D’Arienzo, "Veneziani in Portogallo e portoghesi a Venezia nell'Età delle scoperte", pp. 427-443. AirAldi, "Portoghesi tra tre mari”, pp. 110-117.
} 
instaladas en Barcelona y Valencia9. Luis Adão da Fonseca en sus trabajos sobre los portugueses en el Mediterráneo Occidental y el corso aporta algunas referencias de los lusos en Mallorca, pero no elaboró un estudio específico de su papel en las islas Baleares. Themudo Barata estudió la actividad de la comunidad de portugueses en Génova, Barcelona y Valencia, y señala que su presencia en las islas Baleares fue menor, pues tuvieron un papel secundario en el comercio en Mallorca. Afirma que en la segunda mitad del siglo XV aún existían dificultades para los navíos portugueses en los puertos insulares ${ }^{10}$. Circunstancia que Gourdin define como "faiblesse", frente al mayor protagonismo de los lusitanos en el comercio barcelonés ${ }^{11}$.

Desde la historiografía francesa, valenciana, catalana y aragonesa se ha profundizado en el análisis de las relaciones comerciales y humanas entre estos espacios de la costa mediterránea y Portugal ${ }^{12}$. Asimismo, los historiadores mallorquines han abordado la presencia de portugueses en la isla desde la conquista por parte de Jaime $\mathrm{I}^{13}$. Ortega Villoslada ha analizado los intercambios comerciales entre Mallorca y Portugal y ha destacado la presencia de un número no muy elevado de portugueses afincados en la isla desde 1229 hasta comienzos del siglo $\mathrm{XIV}^{14}$. En realidad, su actividad no ha dejado demasiadas huellas en la documentación mallorquina, que es protagonizada principalmente por marineros y mercaderes foráneos procedentes de la península itálica y del sur francés ${ }^{15}$. No obstante, Dufourq aunque pone el foco en la actividad de genoveses, pisanos, florentinos, sardos, venecianos y sicilianos, dedicó unas breves notas a la llegada de barcos portugueses a la isla desde la década de los años veinte del siglo XIV ${ }^{16}$. Asimismo, Sevillano Colom

\footnotetext{
9 Véanse los estudios clásicos: Heers, $O p$, cit. Madurell Marimon, $O p$ cit.

10 Themudo Barata, Navegação, comércio e relações politicas, pp. 80-81.

11 Gourdin, Philippe, "Présence portugueise", pp.130-142. p. 138.

12 En los últimos años se ha profundizado en el estudio de las relaciones comerciales entre Valencia y Portugal, véase, Muñoz Pomer, "El eco de Portugal", pp. 61-84. Muñoz Pomer y Navarro Espinach, "Los mercaderes y la fiscalidad", pp. 195-257. Iradiel e Igual, "Del Mediterráneo al Atlántico", pp. 143-194. Muñoz Pomer, NaVarro Espinach e Igual, "El comercio de importación portugués en Valencia" pp. 11211133. Muñoz Pomer, Navarro Espinach e Igual, "El comercio portugués en el Mediterráneo occidental durante la Baja Edad Media", pp. 73-84. También se han analizado algunos aspectos la actuación portuguesa en Cataluña, Ferrer Mallol, "Productes del comerç catalano-portuguès", pp. 137- 163. Asimismo, se han publicado algunos trabajos sobre los lusos en el reino de Granada tras la conquista. López BeLtRÁN y GonzÁlez Arévalo, "Portugueses en el Reino de Granada", pp. 309- 338. Acerca de la actividad de los portugueses en el Maghreb, véase Gourdin, "Présence portugueise", pp.130-142.

13 En la actualidad Calderón Medina está desarrollando un proyecto de investigación sobre el gobierno del infante don Pedro de Portugal, señor de Mallorca.

14 Ortega Villoslada, "Ciudadanos atlánticos", pp. 347- 359, menciona a algunos de los acompañantes del infante Pedro de Portugal, y a seis patrones, originarios de Lisboa en 1332, 1336, 1340: A. Vinagre, Brenso Bugayo, Esteban Ibáñez, Lorenzo Bugay, Esteban Maladí, Domingo Peris, Marcos Peris, Domingo San Juan, pp. 353-354. Idem, "Dinis, Sancho I de Mallorca", pp. 61-68, p. 62. Véase, Idem, El reino de Mallorca y el mundo Atlántico, pp.255-257 y 261. IdEm, "Oporto y Mallorca", http://www.citcem.org/ encontro/pdf/new_02/TEXTO\%20-\%20Antonio\%20Ortega\%20Villoslada.pdf, [Consultado 10/09/2018] 15 Acerca de las actividades comerciales de pisanos y florentinos en la isla, véase HoussaYe- Mchienzi, Datini, Majorque et le Maghreb

16 DufourQ, "Aspects internationaux de Majorque", p. 30. Menciona también el establecimiento de 130 judíos portugueses que llega a Palma en 1394.
} 
estudió someramente las relaciones comerciales entre Mallorca y Portugal ${ }^{17}$. Pero además de la actividad comercial desarrollada por los lusos, también se ha analizado el nacimiento y desarrollo del consulado de castellanos y portugueses en Mallorca, institución que los representaba en la isla. El cargo de cónsul fue ostentado por castellanos afincados en la isla o por mallorquines, pero no se ha registrado el nombramiento de ningún cónsul originario de Portugal, lo que demuestra su papel secundario en la institución ${ }^{18}$.

Aunque los trabajos previos han puesto el foco principalmente en el aspecto mercantil y las relaciones comerciales entre la isla y el reino atlántico, la realidad es que la presencia y actividades desarrolladas por los portugueses en la isla de Mallorca a lo largo de los últimos siglos medievales, son en gran medida desconocidas. En este trabajo a través, principalmente, del análisis de la documentación notarial mallorquina, se estudiará a los lusitanos que por diversas circunstancias pasaban por la isla, mayoritariamente marineros, mercaderes y peregrinos ${ }^{19}$, y a quienes se establecieron en ella durante un largo periodo de su vida, y trabajaron como menestrales de diversos oficios, fueron escuderos, se dedicaron a la agricultura, o a los oficios relacionados con el mar.

\section{Los portugueses en "Ciutat de Mallorques"}

Ciertamente, el estudio de los portugueses en Mallorca no ha sido abordado en profundidad. Los protocolos notariales conservados en el Archivo del Reino de Mallorca aportan algunas noticias de individuos lusos que se establecieron en Mallorca durante

17 Sevillano Colom, "De Venecia a Flandes", p.26.

18 Cateura BennÀsser, "El consulado medieval de Castilla en el Reino de Mallorca”, pp. 289-298. SzÁszDI León-Borja, "Sobre el consulado castellano en Mallorca”, pp. 215-232. Ferrer Mallol, "De nuevo sobre el consulado de castellanos en Cataluña", Gourdin destaca el mayor poder que los lusos tuvieron en el comercio en Barcelona donde nombraron un cónsul portugués en 1420, Gourdin, Op cit, p. 138.

19 La presencia de peregrinos portugueses en el Mediterráneo está ampliamente constatada, Themudo Barata analizó algunos casos, Themudo Barata, Op, cit, p.199. Hinojosa señala el papel de dos piratas mallorquines que asaltaron una nave procedente de Lisboa en la que se encontraban numerosos peregrinos que se dirigían a Roma. Los portugueses se quejaron a los jurados valencianos que argumentaron que no podían resarcirles sus bienes, puesto que se trataba de piratas mallorquines, HinOJosa Montalvo, "De Valencia a Portugal", p. 158. En 1395 hay noticias en Mallorca de la presencia de una familia portuguesa integrada por un hombre llamado Juan, su esposa y su hijo que regresaban de Tierra Santa y que, como consecuencia de una enfermedad, tuvieron que detenerse en la isla. Su situación económica era precaria y por ello la curia eclesiástica ordenó a los párrocos de toda la diócesis a que exhortaran a sus fieles a dar limosna para el sustento de esta familia portuguesa. Rosselló VAquer, Noticiari de Felanitx, p. 89. En la segunda mitad del siglo XV, procedentes de Roma, aunque no es posible conocer si lo hacían como peregrinos, pero es lo más probable, o con alguna misión específica para el Papado, llegaron en una galera veneciana a la ciudad de Mallorques el Tesorero de la catedral de Oporto y el Prior de Arruda cuya visita a la ciudad y posteriormente su viaje a Ibiza y regreso a Mallorca ha sido transmitido por la Crónica de Portugal de 1419 .

20 La documentación escrita en catalán se refiere en la mayor parte de las ocasiones como "Ciutat de Mallorca" o "Ciutat de Mallorques", en ocasiones como "Ciutat". Todas estas denominaciones se refieren a la actual ciudad de Palma. 
los últimos siglos medievales, o que, por diversas circunstancias, pasaban por la isla. Es una rica y diversa documentación, entre la que se encuentran contratos de aprendizaje, de matrimonio, reconocimientos de deudas, nombramientos de procurador, testamentos, litigios, compras, ventas, etc., que permiten conocer ciertos aspectos de la población de origen lusitano establecida en la isla, aunque aportan una perspectiva sesgada de cómo se integraron en la sociedad mallorquina, y sólo permiten ver algunos indicios de una cierta colaboración entre los conterráneos ${ }^{21}$.

Los protagonistas de la documentación son fundamentalmente hombres cristianos. Muchos de ellos casaron con mallorquinas, integrándose así en la sociedad insular. Sólo se ha registrado un caso en el que una mujer declare su origen en el reino atlántico en el periodo analizado ${ }^{22}$ : se trata de la portuguesa Isabel, que fue concubina de Joan Gordiola, un hostalero leridano establecido en "Ciutat" conservadas en los protocolos notariales son de cristianos, pero la noticia de la llegada de ciento cincuenta judíos portugueses que arribaron a la ciudad en 1394, atraídos por la política regia para dinamizar el comercio entre la isla y el norte de África tras el ataque a la judería mallorquina en $1391^{24}$, indica que el número de judíos de origen lusitano en el call mallorquín pudo ser significativo; a pesar de que algunos de ellos se trasladaran con posterioridad a Venecia, Barcelona y Valencia ${ }^{25}$.

En pocas ocasiones es posible conocer la localidad de origen de los lusitanos avecinados en la isla, aunque se conservan algunas referencias a hombres nacidos en Lisboa, localidades cercanas como Sintra, o en el Algarbe ${ }^{26}$. Parece que este es el área geográfica mayoritaria de procedencia ${ }^{27}$, pues no se han localizado testimonios en los que desta-

21 Esta cierta cohesión del grupo de portugueses habitantes en la isla, se observa en que muchos de ellos eligieron como procuradores para resolver sus litigios a sus paisanos o como testigos de sus asuntos jurídicos.

22 Sevillano Colom, "De Venecia a Flandes", p. 26 y ss. La bibliografía publicada apenas ha hallado testimonios de mujeres de origen portugués, a excepción de Berengueria de Lixbona, OrTEGa VillosladA, "Ciudadanos atlánticos", p. 63.

23 El 28 de junio de 1446 reconocen una deuda de 28 florines y medio de oro al mercader Galceran Gual. Rosselló Vaquer y Bover Pujol, "El sexe a Mallorca", p. 77

24 Sevillano Colom, "De Venecia a Flandes" p. 26 y ss. Acerca de las vinculaciones comerciales de los judíos mallorquines con el Norte de África, veáse ABUfalia Un emporio mediterráneo. pp. 270-274. Sobre la actividad de los judíos portugueses en el comercio mediterráneo, véase THEMUdo BARATA, $O p$, cit, pp. 214-215.

25 Dufourq, "Aspects internationaux de Majorque", p. 30. Las condiciones con las que los judíos de Mallorca comerciaban con el norte africano véase, HoussaYe- Michienzi, "Entre Majorque et l'Afrique", p. 155- 159. Idem, Datini, Majorque et le Maghreb, pp. 414-435.

26 Se documenta la presencia en Mallorca de varios hombres de la localidad de Lagos: ARM, Prot. C-185, f. 22r. y Bernardus Balier en 1504, ARM, Prot. C-263, f. 83v-84v. Portimão es la ciudad de origen de Joan Ferrandis y Joan Vieres, patrón y señor de la carabela Santa María que venden en 1520 a dos mercaderes mallorquines. Prot. S-1.964, 79v

27 Esta circunstancia está en consonancia con el protagonismo de los puertos de Lisboa, Lagos, Tavira, Setúbal con el comercio mediterráneo, especialmente Valencia, en detrimento de los puertos del Norte portugués, cuyo comercio estaba más destinado al Atlántico Norte. Miranda y Faria, "Lisboa e o comerço marítimo com a Europa", pp. 241-266. 
quen que nacieron en ninguna ciudad del norte portugués ${ }^{28}$, aunque sí de un individuo nacido en la localidad interior de Torres Novas $^{29}$. Si bien es cierto que, en la mayor parte de las ocasiones, sólo utilizan el locativo de una manera generalizada, empleando expresiones como "portugués", u "oriundus Regni Portugalis", lo que esconde su tierra natal. Asimismo, los notarios mallorquines solían adaptar la grafía del nombre y patronímico en portugués al catalán o al latín; lo que en ocasiones puede dificultar la identificación de los individuos.

Los lusitanos se integraron durante las últimas decenas del siglo XIV hasta los inicios del siglo XVI, en la sociedad populosa y cosmopolita mallorquina, aunque ciertamente, representan una minoría. La conquista de Ceuta en 1415 fue un hito fundamental que convirtió a los portugueses en un nuevo actor en el comercio mediterráneo. Asimismo, la conquista de las islas de Azores y Madeira, además del acceso al África negra, afianzó las rutas comerciales portuguesas en el Mediterráneo al incorporarse al comercio de nuevos productos como el azúcar y los esclavos, además de la exportación de pescados, cueros y corcho ${ }^{30}$. Desde entonces, se registra un ascenso de su presencia y actividad en el archipiélago balear. Pero, a pesar de ello, representaban menos de un dos por ciento de los individuos de origen foráneo establecidos en la isla de Mallorca ${ }^{31}$.

\subsection{Menestrales. La actividad manufacturera}

Los portugueses no han dejado demasiadas huellas en la documentación insular, aunque la mayor parte de ellos eran hombres marineros y mercaderes, o dedicados a los oficios relacionados con el mar; una minoría se dedicó a otros oficios, que les permitieran mantenerse en la ciudad. Themudo Barata analizó este comportamiento de los lusitanos en Génova y Barcelona ${ }^{32}$. El caso mallorquín es similar, pues, a pesar de las políticas proteccionistas gremiales que dificultaban en gran medida la integración de individuos de origen foráneo en los gremios de la ciudad, se han conservado varias referencias a la presencia de artesanos portugueses en distintos gremios de Palma. Algunos de ellos casaron con mujeres isleñas e integraron a sus hijos como aprendices en los talleres de los maestros mallorquines ${ }^{33}$. Sin embargo, no se ha registrado a ningún portugués con

\footnotetext{
28 Sólo se ha conservado una referencia explícita al Tesorero de la Catedral de Oporto que está de paso en la isla procedente de Roma

29 ARM. Prot. F- 121, fol. 16v-17r. "Alfonso de Torres, marinario, oriundo civitatis de Torres noves, regni Portugalis, nunc vero habitatore maioricarum”. Se trata del marino Alfonso de Torres que en 1447 casa con Catalina Torrella.

30 Muñoz Pomer, "El eco de Portugal", p. 64.

31 Vaquer BennÀssar, "Inmigrants a Mallorca”, p. 121. El autor sólo ha documentado a once portugueses durante este periodo.

32 Se puede observar la diversidad de oficios a los que se dedicaron los portugueses avecinados en Valencia entre 1308 y 1449, además de mercaderes y marineros, fueron zapateros, juboneros, lapicidas, azucareros, y escuderos. MuÑoz Pomer, "El eco de Portugal”, p. 80.

33 Acerca de las ordenaciones relativas al aprendizaje en la isla véase, SANTAMARÍA, "La formación profesional en Mallorca”, pp. 651- 668.
} 
taller propio en ninguno de los oficios de la ciudad, lo que indica que no tuvieron un papel destacado en el ambiente manufacturero insular.

Entre los menestrales dedicados al oficio de la lana se encontraban los tintoreros ${ }^{34}$. Son varios los lusos que ejercieron este oficio en Mallorques, como Álvaro Piris, quien en 1467 nombraba como procurador a Juan Gonsalvo, también portugués, para que cobrara cantidades que le eran debidas ${ }^{35}$, o Juan Narro, que casó con Joaneta, hija de un tendero mallorquín y vivió en la parroquia de Santa Eulalia ${ }^{36}$. El mismo oficio compartía Pedro, "tinctorius, oriundus civitatis et regni de Portugal, nunc comorans in presenti civitate maioricarum", quien en 1496 firma un contrato de aprendizaje para integrar a su hijo Lorenzo, de diez años, en el taller del zapatero Damià Galmés, "causa addicendi", durante un periodo de seis años. En ese tiempo, el maestro estaba obligado a proporcionar al niño comida, bebida, vestimenta y calzado. Al finalizar el contrato, debía vestirlo de nuevo ${ }^{37}$.

En el gremio de zapateros se integraron varios portugueses en las últimas décadas del siglo XV; como un hombre llamado Pedro ${ }^{38}$, casado con Violante, quien en 1482 nombraba como procurador a Lleonard Torrella, también zapatero, para que cobrase las cantidades que se le debían, aunque no se conoce quién era el deudor ni el motivo de la deuda $^{39}$. Unos años después, un escudero portugués llamado Juan, firma un contrato de diez años de duración por el que coloca a su hija Mónica ${ }^{40}$, de unos doce años, para que sirva en el taller del zapatero Pere Roselló. En este caso el maestro no estaba obligado a enseñarle el oficio, ya que el trabajo de la niña estaba motivado "causa servendi", pero se comprometía a darle de comer, beber, calzar y vestir y, al final del tiempo del contrato, debía entregarle la copiosa cantidad de 20 libras. Aunque el documento no lo explicita, esta cantidad solía estar destinada a cubrir la dote matrimonial de la niña quien, transcurridos los diez años de servicio en casa del zapatero, habría alcanzado la edad núbii ${ }^{41}$. Parece que la vinculación de Juan con los zapateros era estrecha, pues actúa como testigo en un acto por el que el zapatero Antoni P, nombra procurador a Arcís Comte, un mercader de Cagliari para poder cobrar unas cantidades que le eran debidas. ${ }^{42}$

\footnotetext{
34 Desarrollaban su actividad principalmente en el espacio extramuros de la ciudad denominado "El Camp dels tints", Barceló Crespí y Rosselló Bordoy, La ciudad de Mallorca, pp. 136-137. Sobre su actividad véase BERNAT I ROCA, Els "III mesters de la llana": Paraires, Teixidors de Llana i Tintorers, Idem, "De la companyia al monopoli", pp. 443-460. BARCELó Crespí, "Problemàtica del Gremi de Tintorers devers 1487”, pp. 223- 234.

35 ARM, Prot. M-255, f. 73r.

36 Roselló Lliteras, Registra Sponsalium, Vol III, anotación 53, p. 12. El matrimonio se celebró el 4 de agosto de 1460.

37 "Providere in cibo et potu, calciatu et vestitu tanto sano como enfermo y et in fine temporis vestire eum de novo". ARM, Prot. M-271, f. 52v.

38 ARM, Prot. M-271, f. 52v.

39 ARM, Prot. M-427, f. 18v.

40 Esta onomástica no es habitual en la isla, por lo que este nombre de pila podía pertenecer al stock de "nomina maiorum" de la familia de Juan.

${ }^{41}$ ARM, Prot. M-434, f. 49v.

42 ARM, Prot. M-429, f. 12r.
} 
También se documenta la presencia de varios "barreters" / birreteros en la actual ciudad de Palma, como Antón Villalobo, "portugues, nunc maioricarum conmorante", que contrae matrimonio en 1496 con Clara, la hija del pelletero Pere Aguiló. El 1 de mayo de 1496, en los esponsales celebrados para acordar el enlace, Pere Aguiló, de acuerdo con su hijo Rafael, promete a Antón entregarle una cantidad de 10 libras. Ese mismo día, se acuerda que el padre de la novia deberá entregar en concepto de dote 60 libras a Antón. Lo hará en dos plazos de treinta libras cada uno: el primero se pagaría el sábado siguiente a la firma del acuerdo y el segundo, en un mes. El matrimonio se celebró el día 4 de mayo en la iglesia de Santa Eulalia ${ }^{43}$. Unos años después, en 1502, un conterráneo de Antón, llamado Diego Ferrandis, también birretero, estaba casado con Isabel, viuda del carpintero Pere Ferrando, que afirma que en el momento de su casamiento, posiblemente acaecido poco tiempo antes, había entregado a Diego una dote de 60 libras $^{44}$.

Pero uno de los grandes focos de atracción para artesanos foráneos fue la construcción, debido a la fama que habían alcanzado los principales maestros y al reciente desarrollo constructivo que había experimentado la ciudad ${ }^{45}$. Ciertamente, la mayor procedencia de aprendices foráneos del gremio de lapicidas era la cuenca mediterránea, aunque también se documenta a dos "lapiscidae" de origen portugués en las primeras décadas del siglo XVI. Procedente de Sintra, llegó a Mallorca el lapicida, Esteban Rodrigo, "oriundo in villa Sintre regni Portugalis" ${ }^{46}$, que casó con una mujer de la isla. El 30 de mayo de 1519 acordó contraer nupcias con Margarita, hija del mercader Jaime Garau, que aportó una dote de 30 libras $^{47}$. El día 8 de noviembre del mismo año, Esteban reconocía haber recibido por parte de su suegro la cantidad correspondiente a la dote ${ }^{48}$. Dicho documento estaba signado como testigo por Antoni Garau, "lapiscida"49. Esta documentación permite afirmar que el portugués estaba emparentado con uno de los talleres de lapicidas más destacados, cuya actividad se documenta en la ciudad entre $1509 \mathrm{y}$, al menos, $1525^{50}$. Se trata del taller de los hermanastros Baptista y Antoni Garau, que posiblemente eran hermanos de su suegro, Jaume Garau. Juan Vicens apunta la posibilidad de que Esteban fuese discípulo de Baptista Garau, tío de su esposa, y que trabajara a partir de 1520 en la construcción de una fuente en el barrio de Santa $\mathrm{Cruz}^{51}$. Esteban no era un niño cuando

\footnotetext{
43 Roselló Lliteras, Registra Sponsalium, vol III, anotación 173, p. 103. Como testigo de Antón actuó Paulus Vallairosa, y de su esposa Clara, su hermano Rafael.

44 ARM, Prot. T-841, f. 33r-33v.

45 Acerca del gremio de lapicidas en Mallorca véase JuAN Vicens, Lapiscida vel ymaginarius.

46 ARM, Prot. T-467, f. 49v. Repetido en ARM, Prot. T-491, f. 46r.

47 ARM, Prot. T-467, f. 17v-18r. Acerca de la ascensión social de los lapiscidas en Mallorca a través de ventajosos matrimonios, véase JUAN VICENS, "El Estatus social del artesano de la piedra", p. 250. IDEM, Lapiscida vel ymaginarius. pp. 285- 334.

48 ARM, Prot. T-467, f. 49v. Repetido en ARM, Prot. T-491, f. 46r.

49 ARM, Prot. T-491, f. 46r.

50 JuAN Vicens, Lapiscida vel ymaginarius, pp. 280- 283, y p.219.

51 Barceló Crespí y Rosselló Bordoy, La ciudad de Mallorca, pp. 308-309.
} 
se integró en el taller ${ }^{52}$, es muy probable que ya conociera el oficio cuando llegó a Mallorca y que decidiera complementar su formación, como hicieron la mayor parte de los lapicidas foráneos que se establecieron en la isla, atraídos por la maestría de los grandes artistas insulares.

Al mismo tiempo que Esteban, estaba trabajando en Mallorques su conterráneo Joan Gonsalvo, que en 1526 tenía una edad que oscilaba entre los 22 y 25 años, y siendo residente en la ciudad, suscribía un contrato con el maestro de origen siciliano Joan Oliver $^{53}$, que tenía su propio taller. En él se integraba el portugués por un periodo de dos años, para perfeccionar el oficio. El maestro Oliver lo admitía y le ofrecía 12 libras al año, es decir 20 sueldos cada mes. Además, le entregaría una "barcella" de trigo cada semana durante los dos años ${ }^{54}$. De nuevo se trata de un artesano de la piedra que se integra en el taller de un maestro, con una cierta relevancia en el gremio, para perfeccionar sus conocimientos en el oficio. Poco más sabemos de estos dos lapicidas portugueses.

\subsection{El servicio doméstico y las actividades agrícolas}

Además de las manufacturas, algunos lusos se dedicaron al servicio doméstico, como Luis Vaz, natural de Lisboa, menor de 25 años pero mayor de 17, que en 1466 se puso al servicio del Pere d'Aguera para trabajar en su hostal ${ }^{55}$. Asimismo, su paisano Fernando de Lisboa el 16 de diciembre de 1482, se colocaba en casa de Huguet des Mas, ciudadano de Mallorca. En su contrato de servicio doméstico se hace constar que Fernando debía servir en casa del amo tanto de día como de noche, en todo tipo de tareas, siempre que fueran lícitas y honestas. Por su parte, Huguet des Mas se obligaba a tenerle aunque enfermara, darle comida y bebida, además de 10 libras anuales "pro servitute per me vobis facienda" ${ }^{56}$.

Pero el servicio doméstico fue una de las actividades en las que la presencia femenina fue más abundante ${ }^{57}$. Esta fue la ocupación de Mónica, la hija del escudero Juan que

\footnotetext{
52 Santamaría establece que la mayor parte de las ordenanzas de los gremios mallorquines impedían que los aprendices contrajeran nupcias antes de terminar su periodo de formación, para evitar así tener hijos, mientras no tuvieran medios para mantenerlos. SANTAMARÍA, "La formación profesional en Mallorca", p. 656.

53 Joan Oliver era siciliano. Había llegado a la isla para perfeccionar su oficio en el taller de Guillem Vilasclar, uno de los principales maestros lapicidas de la ciudad. Trabajó en algunas de las principales obras de la ciudad como la catedral y logró abrir su propio taller, con la dificultad que esto suponía para un maestro foráneo. A pesar de ello, tuvo un papel destacado en el gremio. Acerca de su trayectoria véase, JuAN VICENS, Lapiscida vel ymaginarius, pp. 303- 305 y 363. IDEM. "El arquitecto y escultor Joan Oliver", pp. 7-16.

54 ARM, Prot. S-631, f. 25v-26r.

55 Barceló Crespí y Ferrer Vidal, "El servicio doméstico femenino", pp. 207-221. Vaquer Bennàssar, "El contrato de trabajo en la Mallorca medieval", p. 647.

56 ARM, Prot. S-27, f. 97r-97v.

57 Vaquer Bennàssar, "El contrato de trabajo en la Mallorca medieval", pp. 646-647; SASTRe Moll, Jaume, La dona medieval a la ciutat de Mallorca, pp. 128-133.
} 
sirvió durante diez años en el taller del zapatero Pere Rosellós ${ }^{58}$. O de Catalina, hija de un portugués llamado Diego, a la que al fallecer su padre en 1521, y posiblemente por los problemas económicos acarreados por tal pérdida, su madre Magdalena decidió integrarla durante diez años al servicio de Egidi Cirera. Las condiciones del contrato de servicio doméstico fueron las habituales: el señor debía dar de comer y beber a la joven, y tenerla tanto sana como enferma. Al final del contrato se le darían 10 libras además de vestido y calzado nuevo ${ }^{59}$. El mismo destino tuvieron algunas de las esposas de los portugueses al enviudar, como Magdalena, viuda de Juan, "el portugués", que en 1519 se integraba al servicio de la casa de Bernart Albertí para atenderle a él y a su familia ${ }^{60}$. Las actividades agrícolas fueron desempeñadas por braceros portugueses que arrendaban su fuerza de trabajo para cultivar las tierras de un propietario. Es el caso de Gaspar Reus, portugués de oficio agricultor y domiciliado en la "Ciutat de Mallorques", que en abril de 1527 se colocaba con Pere Vicent, tejedor de lana, hasta la fiesta de Navidad, para trabajar en faenas agrícolas en tiempo de la recolección de la cosecha de cereales y en su transporte. Su salario sería de 17 libras mensuales ${ }^{61}$. Pero también, algunos lusitanos fueron propietarios de tierras fuera de la ciudad, como Bernat, portugués, y su esposa Antonina Gotarra, que estaban avecinados en la localidad de Sóller. Ambos vendieron en febrero de 1497 a Joan Sipo una finca de tierra y olivar, situada en el camino que va de Sóller al puerto, por el precio de 30 libras. ${ }^{62}$

\subsection{Escuderos}

Themudo Barata analizaba la presencia de escuderos portugueses en Barcelona y Valencia, del mismo modo se registra en la isla a varios hombres relacionados con la actividad guerrera en el tránsito del siglo XV al XVI. En la década de los años ochenta, se documenta en la ciudad de Mallorca a varios escuderos al servicio de destacados miembros de la oligarquía urbana; como Juan, "de domo magnifici Galcerandi Giner", quien fue nombrado procurador de Martín Ladero, un marinero castellano en agosto de 1483 para cobrar unas deudas ${ }^{63}$. Es probable que se trate del mismo escudero Juan, portugués, que en 23 de enero de 1484 actuaba de testigo en el acto en que Antoni Pi, zapatero, designaba procurador a Arcís Compte, mercader de Cagliari, para poder cobrar ciertas cantidades que le eran debidas ${ }^{64}$; y que había puesto a su hija Mónica al servicio del zapatero Pere Roselló. Un año después, en 1485, hay noticia de la muerte de otro escudero portugués, llamado Juan, que había vivido en la casa de Gaspar de Bordils a quien servía ${ }^{65}$. Es muy probable

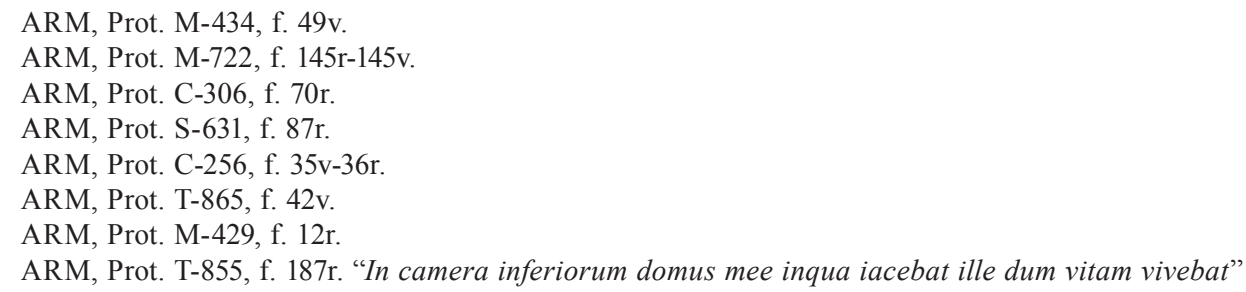


que no tuviera familiares en la isla y que hubiera fallecido sin herederos, pues Gaspar procede a la almoneda de sus bienes, en la plaza de la Cort durante los días 9 y 10 de junio. Entre sus pertenencias se registran distintas piezas de ajuar doméstico y de vestimenta personal, entre las que destacan prendas nuevas y de tejidos caros, como el terciopelo, que indican un cierto poder adquisitivo ${ }^{66}$.

El 12 de marzo de 1488 Pedro Servera, portugués, "nunc scutifer”, y su esposa Coloma junto a otros familiares, vendían al alfarero Andreu Vidal por 40 libras, una casa, situada en la calle de n'Oristany, en la parroquia de Santa Eulalia ${ }^{67}$, que Coloma había recibido en herencia de su padre Joan Blasco ${ }^{68}$. Unos años después, en 1490, otro escudero portugués, llamado Juan, estaba al servicio de Ignasi Torrella ${ }^{69}$.

Los protocolos notariales también permiten observar la movilidad que los escuderos y otros hombres relacionados con el ejercicio de la guerra, tuvieron entre los territorios peninsulares gobernados por el rey de Aragón, y entre las islas del archipiélago. Es el caso de un espadero portugués llamado Álvaro que, antes de establecerse en Mallorca en 1499, había servido al rey Fernando II en Menorca. Parece que se instaló definitivamente en la ciudad, tal vez siendo de una edad avanzada y sin haber tenido descendencia; pues ese año donó sus bienes, presentes y futuros, a la hostalera Elionor para que cuidase de él ${ }^{70}$. Asimismo, antes de establecerse en Palma al servicio del doncel Pere Malferit, el portugués Andrea Vas había permanecido en Lérida, donde aún tenía propiedades en $1514^{71}$.

\footnotetext{
66 ARM, Prot. T-855, f. 187r-188v. Entre sus propiedades se encuentran algunas de las piezas de su armadura, como "unes calces de malla" que fueron vendidas por 1 libra y 9 sueldos a Joan Sard, quien también adquirió "una falda de malla sotil" por 17 sueldos, y "hun guant de malla" por 3 sueldos y 10 diners; además de otras como "unes manegues de malla" compradas por Francech San Martí por 13 sueldos, o "hun jaquet de malla" vendido a Joan Trobar, por 1 libra y 5 sueldos. Pero también otras prendas de vestir de buena calidad por las que se pagó una importante cantidad, como "una capa negre bona" adquirida por Miguel Carbonell por 3 libras, 3 sueldos y 2 diners, "un gipò de Xemellot morat ab mitges mànagues de vellut negre", comprada por 1 libra y 11 sueldos por Joan Torres, "huns guants de pell" vendidos por 1 sueldo y 8 dineros; "Hun barret burell" comprado por Ramón Ça Nov por 2 sueldos y 10 diners, o "hun cint de cuyro negre ab floch" adquirido por Jaume Vila por 9 sueldos; o varios pares de calzado como "huns borseguins de moltó" adquiridos por 8 sueldos y 2 diner por el hornero Miguel Carbonell, o "unes sabates blanques" vendidas a LLuc Alemany por 4 sueldos y 6 diners. Aunque también se encuentran prendas gastadas como una "capa grisa vella" que fue comprada por Joan Pinya por 1 libra y 12 sueldos; "un sayo de drap negre", vendido a mossén Joan Rabassa por 1 libra y 12 sueldos; "un sayo morat vell et tot squinsat" comprado por Anto de Civilla por 4 sueldos, "unas calces de rosat velles e squinsades" vendidas a Jaume Colom por 9 sueldos. Entre sus propiedades también se registran varias piezas de ajuar doméstico o unos naipes, que fueron vendidos a Joan LLorenç por 1 sueldo.

${ }_{67}$ Barceló Crespí y Roselló Bordoy, La ciudad de Mallorca, pp. 155-301. La parroquia de Santa Eulalia se situaba en la zona áulica de la ciudad, aunque su casa posiblemente era austera, dado el precio que se pagó por ella.

68 ARM, Prot. T-823, f. 96v-97r. La onomástica de Pedro parece estar adaptada del apellido portugués Cerveira.

69 ARM, Prot. A-101, f. 20r.

70 ARM, Prot. C-198, f. 160r.

71 ARM, Prot. N-26, f. 2r. En enero de 1514 nombraba procurador el mercader Joan Ollers para que recuperara lo que le pertenecía en Lleida.
} 
Parece que mayoritariamente los escuderos portugueses se trasladaron a la isla en solitario y que entraron al servicio de los miembros de la oligarquía urbana mallorquina. Algunos de ellos permanecieron solteros y no tuvieron descendencia, mientras que otros casaron con mujeres insulares de las que tuvieron hijos, que se integraron en los oficios de la ciudad. A la vista de los protocolos notariales, parece que su poder económico era modesto, pero tenían un cierto poder adquisitivo, pues algunos eran propietarios de casas en la zona más destacada de la ciudad, conservaban bienes en otros lugares en los que habían residido y entre su indumentaria personal tenían algunas prendas de gran calidad.

\section{Las gentes del mar: marinos y mercaderes}

Los protocolos notariales mallorquines aportan numerosas noticias sobre la vida y ocupaciones de varios individuos dedicados a las actividades marineras y comerciales, como patrones de naves y carabelas ${ }^{72}$, marineros que trabajan para un patrón ${ }^{73}$, y otros propietarios de embarcaciones que ellos mismos patroneaban o que alquilaban a los grandes mercaderes mallorquines ${ }^{74}, \mathrm{y}$ mercaderes. Pero también de otros dedicados a ciertos oficios vinculados al mar como apuntadores, barqueros, pescadores, carpinteros de ribera, guardianes del mar, calafates, etc ${ }^{75}$.

Muchos de ellos moraban en el arrabal del mar, en la parroquia de Santa Cruz, un barrio populoso y en el que convivían gentes de diversas procedencias vinculadas a los oficios del mar y al comercio. En él habitaba el calafate portugués llamado Juan que casó en 1420 con una mujer llamada Práxedes ${ }^{76}$; o Fernando, también calafate, que en 1513 ejerció como procurador elegido por el portugués Gonzalvo Orrea, que moraba en Ibiza, para que reclamara una deuda en su nombre ${ }^{77}$. Este comportamiento pone de relieve una cierta cohesión del conjunto de los lusos que habitaban en aquel momento en las islas, pues se elegían como representantes de otros conterráneos para solventar los conflictos que pudieran acontecer en el ejercicio de su actividad. A pesar

\footnotetext{
721 de diciembre de 1520 Jordi Ferrandis y Joan Vieres de Portimão, patrón y señor de la carabela Santa María, la venden a Miquel Nadal y Martí Roig, mercaderes, por 210 ducados. VAQuER BenNÀssar, El comerç maritim de Mallorca, p. 214. Asimismo, en 1502, "Johanes Ibaniez dominus et patronus, portugalenses, nunc residens in Maioricis", vende su carabela, llamada Santa Catarina, a Bernat Gil, marinero, Albert Moll notario y a Joan Miquel mercader, ciudadanos de Mallorques, con todos sus aparejos y derechos por 65 ducados. ARM, Prot. S-884, 142.

73 En 1487 Lluís Berenguer, patrón de nave, admite que debía a Sebastià Suris 7 libras y 12 sueldos por los servicios prestados en su nave. ARM, Prot. C-206, f. 10v.

74 Alfonso, marinero portugués, alquiló en 1499 su bergantín a Pere Pardo. ARM, Prot. C-198, f. 130v.

75 Barceló Crespí, El Raval de la mar, pp. 105- 124. Barceló Crespí y Roselló Bordoy, La ciudad de Mallorca, p.320.

76 Era viuda del marinero, Joan Castelló. VAquer Bennàssar, Concessos segle XV, http://www.llinatgesdemallorca.com/category/segle-xv/concessos/ [Consultado 18/09/2018]

77 ARM, Prot. M-600, f. 119r-119v, y ARM, Prot. M-491, f. 52r-52v. El sábado 8 de enero de 1513 la deuda ascendía a 3 libras y 10 sueldos, que le eran debidos a Gonçalvo por parte de Alfonso, zapatero de Mallorques.
} 
de que Fernando era calafate, parece que tenía un cierto poder adquisitivo, pues en su testamento, su esposa Catalina dona a la virgen de la Parroquia de Santa Cruz "unum colar auri que sunt quatuor dotzenas et quatuor grans" "78, un ornamento poco habitual entre los avecindados en el populoso barrio de Santa $\mathrm{Cruz}^{79}$.

En la misma parroquia moraba también un marinero portugués llamado Lorenzo, que estaba casado con la mallorquina Margarita Totosaus, quien el 1 de julio de 1484, estando enferma, dicta testamento, "intus domum et cameram domorum ipsius Laurencii portogues". En él nombra heredero universal a "dictum Laurentium portuogues, maritum meum" ". Parece que no tenían hijos, pues no son mencionados en el testamento. Margarita expresa su voluntad de ser enterrada en la Iglesia de Santa Cruz, en el túmulo de la compañía de presbíteros. Los bienes de la mujer eran escasos, lo que indica que su condición social era baja ${ }^{81}$.

Estos son sólo unos ejemplos, de cómo se instalaron en la ciudad de Mallorca y cómo se integraron en la sociedad marinera mallorquina, a través del matrimonio con mujeres insulares. Ello les garantizaba una red de solidaridad familiar, construida mediante el parentesco por afinidad que permitía una mejor integración y que les socorría en los momentos de necesidad, como en la viudedad o en la orfandad. Así, se han conservado algunas noticias de cómo los tíos maternos, ayudaron a los hijos de los portugueses tras la muerte de sus padres, ante la lejanía o la ausencia de la familia paterna. Éste fue el caso de la huérfana Leonor, hija del marinero portugués Antonio Amat y Juana, a quien sus tíos maternos, Lucas Marsà y Catalina, se encargaron de pactar su matrimonio y de aportar su dote marital, además de convertirla en su heredera ${ }^{82}$.

Pero, ¿cómo fueron sus actividades? En verdad, la presencia de marineros y mercaderes portugueses aumentó en todos los puertos del Mediterráneo occidental tras la toma Ceuta. Esta circunstancia se constató en Valencia, donde la presencia de comerciantes y marineros lusos aumentó, y tuvo su repercusión en el Archipiélago; pues muchos

\footnotetext{
78 ARM, Prot. M-654, f. 264r.

79 En este barrio también moraban el portugués Gonzalo y su esposa, Graciosa, que en 1441 vendieron una casa de su propiedad a Joan Amorós y su mujer, sita "extra portale Sancti Hohannis in insula dicta dels Remolars in vico de les Estores" por 19 libras. ARM, ECR 489, f. 182v. BARCEló CRespí, El Raval de la mar, p. 143.

80 ARM, Prot. S-60, f. 146r-146v.

81 Elegía sepultura en la iglesia parroquial de Santa Cruz, en el túmulo de la cofradía de presbíteros. Sólo dejaba 5 sueldos al rector de dicha parroquia en concepto de "ius parrochialis". Esta cantidad es la habitual. Indicaba que le celebrasen las misas de San Amador "pro anima mea" y de todos los fieles difuntos, para lo que dejaba 40 sueldos. Al mismo tiempo añadía también las misas de la Sirventa. Todas estas misas eran habituales entre la sociedad del momento. A su hermano y albacea Salvador le legaba una "gramalla de drap de dol amb capiró"; a su madre Pelegrina, 3 libras. Son los legados mínimos pues no hay referencias a conventos, hospitales, etc. Designaba heredero a su marido pero, en el caso que éste muriera antes que ella, indicaba a su hermano que sus bienes fueran vendidos en "encant" público y que la cantidad recaudada se empleara en la remisión de su alma, la del marido y de todos los fieles difuntos. 82 ARM, Prot. T-461, f. 34r-35v. El documento está fechado el 17 de marzo de 1513. Además de ello, parece que Lucas y Catalina no tenían hijos pues la convirtieron en su heredera.
} 
de ellos, avecindados en la ciudad del Turia ${ }^{83}$, fletaron en ella sus embarcaciones con destino a las islas Baleares, convirtiéndose así en transportistas de valencianos y mallorquines $^{84}$. Éste parece ser el caso de Vasch Alfonso Berrosa, un portugués vecino de Valencia, que el 17 de agosto de 1433 elegía para que actuase como su procurador a Luis Rodi, cónsul en Mallorca de castellanos y portugueses ${ }^{85}$; lo que hace suponer que tal vez tuvo algún conflicto relacionado con su actividad mercantil, del que no se han conservado más referencias.

Unos años después, en septiembre de 1465, las fuentes permiten conocer a otro marino portugués afincado en la ciudad de Valencia, que transportaba mercancías hasta la isla Balear. A pesar de que no es posible conocer las mercancías que transportaba, parece que en el puerto mallorquín el portugués Alfonso López, patrón de bergantín de la ciudad de Valencia, recibió 6 libras de la Procuración Real, "per aportar certes letres reals ab lo dit seu bergantí a una nau en lo port de Portopetro de la present illa la qual anava en les parts de Cerdenya e de Sicília". Estas cartas eran de aviso de la "beneventurada victòria e conquesta feta pel rei de la vila de Cervera" "Como destacó Fonseca, entre 1464 y 1466 la navegación portuguesa había aumentado en el Mediterráneo debido a la guerra que enfrentaba al Condestable Pedro de Portugal con Juan II de Aragón ${ }^{87}$. A pesar de tener el mismo origen que el Condestable Pedro de Portugal y de la campaña de este último por tener a su servicio a numerosos barcos portugueses $^{88}$, Alfonso López estaba comunicando la victoria de Juan II de Aragón en la guerra que los enfrentaba. Posiblemente, había optado por apoyar al aragonés ya que estaba afincado en Valencia, uno de los principales centros de apoyo de Juan II, que era, además base de su negocio ${ }^{89}$.

Pero además del transporte de mercancías desde Valencia, Mallorca fue utilizada por muchos portugueses como plataforma intermedia desde la que continuar el comercio hacia otros destinos, como los principales puertos italianos o el Magreb. Así, se documenta la presencia de varias naves de portugueses que desde la isla se dirigían a

\footnotetext{
83 Los testimonios de presencia de portugueses en Valencia son numerosos. El comercio con Portugal aumentó de manera exponencial hasta el hecho de crear el impuesto "Dret dels portuguesos".

84 Hinojosa Montalvo, "De Valencia a Portugal", p. 155. Describe un suceso acaecido en 1456 en el que una nave portuguesa capitaneada por Andrés Gallardo y cargada de productos textiles zarpó del puerto sin esperar a los dueños de la mercancía. MACAIRE, Majorque et le comerce international, pp. 98-99, Macaire recoge la presa en 1413, de una nao portuguesa de Lorenço Yanyez que salía de Valencia cargada con 85 musulmanes, cuando iba a arribar a Ibiza fue presa por la nao del castellano Juan de Bermeo y la galiota del mallorquín Cristòfol Murta.

85 ARM, Prot. M-127, f. 60v-61r.

86 ARM, RP 3.573, f. 87r.

87 FonseCA, Navegación y corso, pp. 33-34.

88 IDEM, Ibidem, pp. 34 y ss. En el archipiélago balear también se registran barcos al servicio de Pedro de Portugal, como un ballener luso que socorría a Maò en la guerra contra el monarca aragonés, en el que fueron apresados Joan Noya y Joan de Ruilla, que en 1466 fueron apresados y condenados a galeras por ser rebeldes al rey. ARM, RP 3.571, f. 89r.

89 Muñoz Pomer, Navarro Espinach e Igual, "El comercio de importación portugués”, p. 1125.
} 
los puertos italianos de Savona ${ }^{90}$, Gaeta $^{91}$, Nápoles $^{92}$, Civitavecchia y Palermo; o hacia distintos puertos norteafricanos ${ }^{93}$.

La expansión portuguesa en el Magreb, capitaneada por Alfonso V, aumentó el tráfico de barcos lusos, que zarpaban desde Mallorca, a pesar de las constantes provisiones regias que prohibían a las embarcaciones extranjeras comerciar desde el Archipiélago con los puestos norteafricanos ${ }^{94}$. Los lusitanos establecidos en la isla podían hacer la travesía con sus propios barcos hacia este territorio peligroso, donde algunos de ellos fueron capturados; como João de Soto, nacido en Lisboa, que en junio de 1460, declaraba "qui fui olim capturatus in partibus Barbarie nunch vero habitator in civitate Maioricarum". Es muy probable que João se dedicara al comercio desde Lisboa a Valencia, pues en 1467 paga el "Drets dels portuguesos" en Valencia95, y que después continuara la ruta hacia Mallorca y, desde allí, se dirigiera al Magreb. En 1460 ya tenía fuertes vínculos con la oligarquía valenciana, pues nombra procuradores al caballero Joan de Bonastre, al doncel Jofre de Blanes y al mercader Pere García, domiciliados en Valencia, para que cobrasen una deuda en su nombre ${ }^{96}$. Años después, en octubre de 1515, otro portugués, Esteban Jusart, residente en Mallorca, compraba en Bugía la nao San Andrés, con todos sus aparejos, a su capitán Joan de Mendieta, residente en Trapani, por 1200 ducados venecianos ${ }^{97}$.

En otras ocasiones, los marineros lusitanos formaban parte de la tripulación de barcos cuya propiedad era de mercaderes mallorquines. Así, en septiembre de 1478, Pablo Benet, Alfonso Martí, “àlies portugués”, junto con Joan Pasqual y Francesc de Luna, acuerdan y prometen al mercader Jaume March, que navegarán en su "llaüt”, del que Pablo era patrón, hacia los mares de Orán, para cargar hilo y transportarlo a la isla ${ }^{98}$. Los patrones portugueses también solían alquilar sus naves para llevar a cabo dicho viaje $\mathrm{e}^{99}$. Es el caso del marinero luso Alfonso que alquiló en 1499 su bergantín "pro viagio

\footnotetext{
90 Es el caso de Juan Martí que en 1496 transportaba uvas pasas desde Alicante a Savona, cuando su embarcación fue atacada. Posteriormente lo analizaremos este suceso con mayor detalle.

91 ARM, Prot. C-185, f. 22r.

92 En 1456 Diego de Braga un marinero portugués que habitaba en Nápoles, y que había llegado a Palma donde enfermó, dictó testamento en el que expresaba su voluntad de ser enterrado en la capilla de Santa María la Nueva de Nápoles. Prot. C-173- fol. 7r-8r.

93 Gourdin, Op cit, p. 133. Recoge algunos testimonios de barcos portugueses que comerciaban en la primera mitad del siglo XV con el Magreb, el sur de la península italiana y Sicilia. El comercio con el Magreb desde Mallorca tuvo un gran tráfico desde el siglo XIII. Véase, Sevillano Colom, Mercaderes y navegantes mallorquines, Historia de Mallorca, Palma, 1970, pp. 482.

94 IDEM, Ibidem, pp. 488-489.

95 Muñoz Pomer y Navarro Espinach, "Los mercaderes y la fiscalidad”, p. 255.

96 ARM, Prot. C-181, f. 28r.

97 ARM, Prot. R-328, f. 30v.

98 ARM, Prot. C-206, f. 56r-56v.

99 López Pérez, La Corona de Aragón y el Magreb, pp, 300 y 304. La autora registra sólo dos viajes que parten desde Mallorca con destino al Magreb, capitaneados por portugueses, mientras que documenta varios ejemplos en los que patrones portugueses alquilan sus embarcaciones a mercaderes mallorquines que se dirigen a Bugía.
} 
fiendo Deo volente in partibus Barbarie"100, al converso mallorquín Pere Pardo, uno de los grandes mercaderes de la isla, que comerciaba habitualmente con el Magreb ${ }^{101}$. Pero además de los marineros afincados en la ciudad de Mallorca, hay noticia de otros portugueses establecidos en los puertos norteafricanos que cubrían la ruta desde el Magreb, las costas andaluzas y la isla; como el patrón de carabela, el portugués, Alonso Álvarez de Tánger, que arribó a "Ciutat" con su carabela cargada con 3000 arrobas de harina, procedente de Málaga ${ }^{102}$.

Trigo, vino ${ }^{103}$, hilo, azúcar de Madeira ${ }^{104}$, cuero, uvas de Alicante, son algunas de las mercancías con las que los portugueses comerciaron en Mallorca; pero los esclavos fueron uno de los productos que mayores réditos les granjeó ${ }^{105}$. Themudo Barata aporta algunos ejemplos de compras de esclavos a lo largo de finales del siglo XIV y principios del siglo XV en Barcelona y Valencia ${ }^{106}$. Hasta entonces Portugal había importado esclavos, pero la toma de Ceuta, seguida de la de Guinea y posteriormente la firma del tratado de Tordesillas en $1494^{107}$, convirtieron a Portugal en un reino exportador de esclavos africanos, sin competencia ${ }^{108}$. Mallorca era entonces uno de los principales mercados de esclavos del Mediterráneo ${ }^{109}$. En este jugoso negocio, que abastecía de mano de obra a

\footnotetext{
100 ARM, Prot. C-198, f. 130v.

101 Houssaye- Michienzi, "Entre Majorque et l'Afrique”, p. 158.

102 ARM, EU 29, f. 100v. Sobre las relaciones comerciales de portugueses, el reino nazarí y el Magreb, véase, FÁBregas García, Op cit, pp. 151-173.

103 Themudo Barata, $O p$ cit. p. 112. El autor analizó el papel de los portugueses en este comercio en las costas mediterráneas durante la segunda mitad del siglo XV, y su actividad con los grandes puertos del Mediterráneo como Barcelona. Para el caso mallorquín no se han conservado demasiadas referencias. ARM, AH 679, f. 34r. Ante la falta de trigo debido a una deficiente cosecha, el 29 de diciembre de 1456 los jurados de Mallorca escribían una carta a los consejeros de Barcelona en la que expresaban su protesta. La causa se debía a que una barca procedente de Tarragona y cargada de trigo y vino, capitaneada por Fernando, portugués, fue interceptada y presa por una galiota armada. Los alimentos no llegaron a su destino.

${ }^{104}$ En lo que respecta al azúcar de Madeira que se empieza a producir y a exportar de manera masiva a partir de la segunda mitad del siglo XV, véase Themudo Barata, Op cit. p. 117. En 1481 llega al puerto de la ciudad de Mallorques el ballener de Pedro Vas, cargado con 339 cajas de azúcar de Madeira. ARM, AH 682, f. 32r-32v. El 31 de julio de 1487 el "apotecari" Antoni Riera reconoce tener una deuda con Joan Miguel Joli, ciudadano, de 31 libras, 4 sueldos y 6 diners del precio de 3 quintars y 23 libras de azúcar de Madeira. Asimismo, el 27 de agosto del mismo año, el hornero Baltasar Bogira, reconoce una deuda a Joan Miquel Joli de 28 libras por una carga del azúcar madeirense VAquer BenNÀssar, El comerç maritim de Mallorca, p. 422. En enero de 1505 Los jurados de la ciudad certifican que "Gonzalbo Bareto, portugués, capità de dues calaveres, surtes en lo port de dita ciutat, deu caxes de sucre de la Madera lo qual sucre entén e vol haver descarregar en la predita ciutat per alegrar-se del guiatge de vitualles atorgat en lo present regne per los gloriosos reys de indelible memòria”. ARM, EU 24, f. 64v.

105 Themudo Barata analizó las mercancías que los transportaban en el Mediterráneo occidental. THEMUdo Barata, $O p$ cit, pp, 67-89.

106 IDEM, Ibidem. p. 126.

107 IDEM, Ibidem. p. 127.

108 GonzÁlez Arévalo, "Portugal y el comercio de esclavos en Málaga", p. 104.

109 Themudo Barata ha afirmado que habitualmente el comercio de esclavos por parte de marineros y mercaderes portugueses en el Mediterráneo era un "comercio proibido" y por tanto no constan en la documentación de registro de los puertos. Themudo Barata, Op cit, pp. 104- 105.
} 
los talleres de la ciudad, al servicio doméstico y a las actividades agrícolas ${ }^{110}$, también participaron marineros y mercaderes lusitanos ${ }^{111}$.

La documentación de los años finales del siglo XV permite conocer algunos datos de la vida y actividad de varios portugueses, que comerciaban con esclavos en Mallorca. Uno de ellos fue Juan Martí o João Martins, propietario de varias naves con las que se dedicaba al transporte de mercancías en el Mediterráneo. En 1496 una de sus embarcaciones, surta en la cala de Santa Ponça y cargada de pasas de Alicante, que tenía como destino el puerto de Savona ${ }^{112}$, fue atacada por Sebastiá Suris, que capitaneaba un barco de Joan Liula ${ }^{113}$. Pero, a la luz de las fuentes conservadas, parece que la mayor parte de sus beneficios procedían de la venta de esclavos en "Ciutat".

Se desconoce el momento y las circunstancias en las que Juan llegó a la isla, aunque pudo acontecer al inicio de los años ochenta del siglo XV. Su primera aparición en la documentación insular está datada en 1485, cuando, casado con la mallorquina Damiana Climent, vende al doncel Francesc de Santmartí un esclavo de nación de etíopes, llamado Pedro y de unos doce años de edad, por 55 libras ${ }^{114}$.

En 1490 Juan reconoce que tenía una deuda de 53 libras y 16 sueldos con el notario Tomàs Forns, quien posiblemente era el encargado de producir la documentación de sus negocios. "Pro solvendum dictum vestrum debitum", el portugués entregó como fianza al notario una esclava, de veinte y seis años llamada Llorença, de nación de sarracenos, para que le sirviera en su casa ${ }^{115}$. En febrero de 1491 reconoce, junto a Benet Marquès, que deben a Frances Vitrano, del reino de Nápoles, 42 ducados venecianos de oro, que les prestó para sus necesidades. Prometen pagarle la deuda en 10 días, cuando la carabela del portugués João Pereira, que signa el documento, arribara al puerto de Civitavecchia, Palermo o a cualquier otro puerto ${ }^{116}$. Posiblemente ambos formaban parte de la compañía de ese patrón portugués. El documento también está signado por Salvador Totosaus, el cuñado del marinero portugués llamado Lorenzo, que se ha citado con anterioridad. Esta circunstancia, permite observar una cierta cohesión entre los portugueses y sus parientes afines que habitaban en ese tiempo en el Arrabal del mar.

Juan Martí se había casado en torno a 1480 con Damiana Climent y moraban en la parroquia de Santa Cruz. En 1486 su mujer, que hacía seis días que había dado a luz a su hija Joana, dictó testamento mientras su esposo estaba ausente de la isla ${ }^{117}$. En ese momento la pareja tenía dos hijas: Catalina, de cuatro años, y Juana, que acababa de

\footnotetext{
110 Véase, Mas Forners, Esclaus i catalans. pp. 44-47. Idem, "La incidencia del mercado de esclavos", pp. $77-100$.

111 Acerca de los vendedores portugueses de esclavos en Mallorca Onofre Vaquer sólo ha registrado la actividad de un vendedor en 1524. Vaquer Bennàssar, L'esclavitud a Mallorca. 1448-1500, p. 64 y 148. 112 ARM, Prot. T-495, f. 5v-6v.

113 Embarcaciones portuguesas con destino al puerto de Savona, véase Themudo Barata, Op cit, p. 285.

114 ARM, Prot. P-640, f. 94v.

115 ARM, Prot. R-564, f. 178v-179r.

116 ARM, Prot. C-197, f. 38v-39r.

117 ARM, Prot, P- P- 452, fol. 146r- 146v. "Testamento de Damiana Climent, uxor Johannis portogues marinarii a presente insula absentis".
} 
nacer ${ }^{118}$. Posiblemente Damiana temía por su vida tras el parto y decidió dictar un testamento en que elegía sepultura "in tumulum quem habeo in capella Sancti Anthonii", en la Iglesia de Santa Cruz, un lugar destacado dentro de la propia iglesia. Ordenaba pagar 5 sueldos de "ius parrochialis", y que se celebrasen treinta y tres misas de San Salvador en la iglesia de Santa Cruz tras su muerte. Nombraba albacea a su hermano Climent, y a su hermana, Catalina le mandaba una "gonela" de color verde, el mongil y el manto negro de paño de lana, "racione servitutis michi in mea infirmitate", y hacía herederos a su esposo y a sus hijas. Damiana tenía un cierto poder adquisitivo, pues poseía importantes joyas, como un collar de plata, un collar de perlas, otro de granos de oro y otro de perlas pequeñas, que dejaba en depósito a su hermana Catalina para que las tuviera mientras sus hijas no alcancen la mayoría de edad; entonces, debería repartirlas a partes iguales. Pero también era propietaria de una casa en la puerta Santa Catalina que había heredado de su hermana ya difunta, Margarita. Ordena que se venda, y que el dinero se emplee para pagar el rescate de su sobrino, Antonio Grec, hijo de Margarita, que aún estaba cautivo de los sarracenos, y si éste hubiera fallecido, que la casa pase a manos de Catalina ${ }^{119}$. A la luz de los bienes que poseía Damiana, parece que el comercio de esclavos había granjeado importantes beneficios a la pareja. Las noticias de Juan Martí se pierden en 1493, cuando se fecha la última referencia documental.

Pero Juan no fue el único lusitano residente en "Ciutat", dedicado al comercio de esclavos. Unos años después, Domingo Falco, marinero oriundo del reino de Portugal, está realizando la misma actividad. En 1517 Domingo vendía a Elionor, viuda de Jordi de Dameto, una esclava suya de nombre Caterina, de nación de sarracenos, de quince años de edad por 85 libras $^{120}$. El 27 de octubre de 1518 vendía un esclavo llamado Miguel de diez años de edad, de tierra de sarracenos, al espartero Gabriel Puigderós, por 50 libras $^{121}$. Pocos días después, en diciembre de 1518 , vendía al tejedor de lana Nicolau Güells un esclavo de nombre Aleix de nación de turcos por 75 libras ${ }^{122}$. Domingo continuó con su actividad al menos hasta octubre de 1520 cuando vendió a Antonio, un marinero castellano, su esclava "loram" de nombre Catalina, de unos treinta años, de nación de moros, por el precio de 81 libras $^{123}$.

Pero además de Juan y Domingo que residían en Mallorca, también se documenta la actividad de varios mercaderes de esclavos que estaban de paso por la capital del reino insular, como Bernat de Lagos ${ }^{124}$ y Diego Rodrigues, mercaderes portugueses que, en ese momento, mercadeaban en Mallorca. Ambos vendieron en 1506 al canónigo Joan Borràs un esclavo negro de unos doce o trece años de edad, llamado Juan. El precio era de 41 libras y 12 sueldos. El mismo día, Bernat Balier vendía al también

\footnotetext{
118 ARM, Prot. P-452, f. 146v.

119 ARM, Prot. P-452, f. 146r-146v.

120 ARM, Prot. T-465, f. 75v.

121 ARM, Prot. V-401, f. 12v-13r.

122 ARM, Prot. P-523, f. 37r-37v.

123 ARM, Prot. B-206, f. 137v-138.

124 Se trata de la localidad de Lagos, situada en el Algarbe.
} 
canónigo Gabriel Burguet, una esclava, llamada Catalina, de nación de moros, de diez y siete años de edad por el precio de 40 libras ${ }^{125}$.

\section{Incidentes piráticos entre portugueses y mallorquines}

Pero el acceso de los portugueses al Mediterráneo, además de las actividades comerciales facilitó el incremento de la "ars piratica" en las costas andaluzas, valencianas, magrebíes y también, mallorquinas ${ }^{126}$. Fonseca informa de varios ataques efectuados por portugueses en 1472 a mercaderes mallorquines, acontecidos en las costas del archipiélago y en tiempos de paz entre ambos monarcas ${ }^{127}$.

En una carta dirigida por Juan II de Aragón al patrón de nao, Jordi Sureda, fechada el 20 de junio de 1472, narra que en ese tiempo de paz con el rey de Portugal, varios corsarios portugueses habían atacado, entre otras, a las embarcaciones de destacados mercaderes mallorquines: como una nao de Bertomeu Negre que se dirigía a la ciudad de Mallorca y que fue apresada por dos balleners y una carabela de portugueses; además de otro ballener suyo que había sido apresado en los mares de Córcega. Una carabela de Johan Berthomeu, que antes de arribar a costas mallorquinas cargada de trigo procedente de Sicilia, había sido asaltada por dos carabelas portuguesas ${ }^{128}$. Asimismo, un ballener de Jordi Sureda cargado de diversas mercancías y procedente del puerto de Valencia había sido apresado en el puerto de Andratx por dos balleners y una carabela portuguesa. El último caso que narra la carta de Juan II es el de una carabela de Francí Vidal'129, que "venint de les parts de la Barbería a Mallorqua", había sido apresada por Pascual, portugués ${ }^{130}$.

\footnotetext{
125 ARM, Prot. C-263, f. 83v-84v.

126 Sevillano Colom, "De Venecia a Flandes", pp. 27-28. Hinojosa Montalvo ha recogido algunos casos de ataques corsarios portugueses en la costa valenciana. Hinojosa Montalvo, "La piratería y el corso", pp.55-69. Ortega Villoslada, ha documentado varios ataques de corsarios portugueses producidos a naves mallorquinas en los primeros decenios del siglo XIV. ORTEGa Villoslada, Mallorca y el mundo atlántico, pp. 269-270. LÓPEZ DE COCA CASTAÑER, “Granada y la expansión portuguesa en el Magreb extremo”, pp. 351-367. Actualmente Victoria Burguera Puigserver está realizando su tesis doctoral sobre este aspecto. Acerca de la actividad corsaria de los ataques de corsarios portugueses en las costas del Magreb, véase Gourdin, Op cit, pp. 136-137.

127 FonseCA, Navegación y corso, doc. 7.

128 Acerca de la actividad comercial de Johan Berthomeu y su hijo homónimo, centrada principalmente en el Mediterráneo, véase, Sastre Mold, "La actividad comercial del mercader mallorquín Johan Barthomeu", p. 270. En su inventario "post mortem" se encontraron tres monedas blancas de Portugal. El padre falleció en 1469 en Nápoles, su hijo Johan se hizo cargo del negocio. Johan Berthomeu, padre, había formado una compañía comercial junto a su hermano Bautista y Antonio de Verí y sus hermanos, con base en Palermo.

129 Posiblemente se trata del hermano de Rafel Vidal, que en 1465 compró a Álvaro Alfonso de Lagos, la nao llamada Santa María, que estaba en ese momento surta en el puerto de Palma. ARM, Prot. C-185, f. $22 \mathrm{r}$.

130 FonsecA, Navegación y corso, doc. 7.
} 
Los ataques constantes a los barcos mallorquines por parte de súbditos portugueses provocaron que algunos de los afectados reclamaran a los "Jurats de la Ciutat de Mallorques" que pidieran a los oficiales del reino de Portugal que restituyesen los daños y pérdidas que sus embarcaciones habían sufrido; pero no habían recibido respuesta de los oficiales lusitanos. Ante esta situación, mossén Jordi Sureda, que había apresado un ballener portugués cargado de cuero y otras mercancías, pretendía venderlos en compensación por los daños recibidos por los ataques de los portugueses a sus embarcaciones. Para ello, pedía al monarca que le permitiera vender dichas embarcaciones y mercancías en cualquiera de sus tierras y reinos. Dada la reticencia de los oficiales portugueses a restituir los daños ocasionados, el monarca dispone dar licencia a mossén Jordi Sureda para vender, "los dits balleners, cuyram, robes e mercaderies que presses haveu dels dits portogueses". Además, señala que debe quedar constancia de los precios y que debe haber una carta pública en la que constara el valor de los bienes que había obtenido con la venta para la restitución de los daños que le habían sido ocasionados, y que debe prestar "caució" de restituir la dicha presa cuando le fuera solicitada por el rey ${ }^{131}$. Ese mismo día, el monarca escribe a Francesc Sureda, comendador de Torres e de Guibut, de la Orden de San Juan de Jerusalén, y hermano de Jordi, para comunicarle que éste debe entregarle uno de los balleners libre, para que lo pueda armar y servir al rey. Pero si mossén Jordi no cumplía este mandato regio o retrasaba la entrega de la embarcación a su hermano, debía pagar una pena de dos mil florines de oro $^{132}$.

Tras obtener la licencia regia, parece que Jordi Sureda procedió rápidamente a la venta de los bienes arrebatados a los balleners portugueses. Sólo una semana después, el 27 de junio de 1472, Juan II ordena a su tesorero Guillem de Peralta que entregase a su conseller, el castellano de Amposta, mil florines de oro, procedentes de la parte que pertenecía al rey de la presa de mossén Jordi Sureda. Éste debía entregárselo, como pago de una parte de la dote de la hija ilegítima del rey, Leonor de Aragón ${ }^{133}$, a Luis de Beaumont, II conde de Lerín. La pareja había contraído matrimonio en 1468 para apaciguar el enfrentamiento entre el conde y el monarca aragonés; pero el conflicto entre ambos se recrudeció en 1472 .

\footnotetext{
131 IDEM, Ibidem, doc. 7.

132 IDEM, Ibidem, doc. 4." E en alguna satisfacció de aquells un dels dos baleners presos de portuguesos per lo magnific e amat nostre Mossen Jordi Sureda, patro de nau, germa vostre, vos donam, atorgam, e consentim graciosament e liberal ab la present, lo qual dit balener vous tingau haiau possehrau sense contradicció alguna vos empero dit frare Guillem siau tengut ab lo dit balener armar, servir a nostra Maiestat e aquell no pugau vendre, alienar e en altres parts aportar sense expressa licencia demanada e obtenguda de nostra Maiestat.(...)”.

133 IDEM, Ibidem, doc. 5."Don Joan (...) dehim, encarregam, manam a vos que de les peccunies del procehit de la part pertanyent a nos de la presa dels balaners de portuguesos que Mossen Jordi Sureda, ultimadament en aquest diez passats ha feta ab la sua nau com de quasevol altres pecunies de nostra cort (...) doneu e pageu al venerable religios amat conceller nostre lo Castella d'Aposta mil florins d'or en or, e açó per rahó de pagar aquels mil florins que lo dit Castella d'Amposta ab cartell de sa ma es tengut e obligat al egregi Comte de Lerin en porrata de la dot de la Illustrissima dona Elianor Arago, filla nostra, per lo matrimonio de aquella ab lo dit conde fet"
} 
Se desconoce la resolución de los asuntos de los otros mercaderes mallorquines mencionados en la carta que habían sido atacados por los lusos en 1472, no obstante, resulta muy llamativa la resolución del monarca con los bienes incautados por Jordi Sureda en compensación por los daños que sus embarcaciones habían sufrido. Parece que la precariedad económica y el ambiente bélico movieron a Juan II a tomar esta determinación y permitirle vender los bienes incautados a los dos balleners portugueses, en un tiempo en que las relaciones con Alfonso V de Portugal, eran pacíficas. No obstante, parece claro que esta determinación estuvo provocada por la necesidad del monarca aragonés de dinero para financiar la guerra civil, pues éste fue el destino de la parte que pertenecía al rey de la presa de Sureda y también, parece que uno de los balleners se empleó en la contienda.

\section{Conclusiones}

El análisis de los protocolos notariales conservados en el Archivo del Reino de Mallorca ha permitido conocer el modo en el que la pequeña comunidad de portugueses se integró en la isla de Mallorca durante el siglo XV. Ciertamente, la toma de Ceuta en 1415 y la posterior expansión por el norte de África de los monarcas lusos, además de la guerra entre el Condestable Pedro de Portugal y Juan II de Aragón, provocaron el incremento de la presencia de los lusitanos en el Mediterráneo, y también en la isla de Mallorca. Pero, a pesar de ello, sólo representaban el dos por ciento de los foráneos avecindados en la "Ciutat de Mallorques".

La documentación utilizada ha permitido, desde una perspectiva general, conocer cómo se integraron en la vida de la ciudad. Si bien es cierto que la mayor parte de los lusos que llegaban a la isla eran hombres relacionados con las actividades marineras y mercantiles, se han localizado diversos ejemplos de escuderos y de algunos hombres dedicados a otros oficios como tintoreros, zapateros, birreteros, lapicidas; pero también patrones de carabelas y bergantines, marineros que tenían sus embarcaciones o que trabajaban para otros, que se dedicaban al comercio por el Mediterráneo. De hecho, utilizaron habitualmente la isla como una escala intermedia para travesías con destino a los puertos italianos, pero parece, a la luz de los protocolos, que tuvieron una mayor actividad en los puertos norteafricanos. Entre las mercancías transportadas, además de vino, trigo, cueros y frutos secos, destacaron en el comercio del azúcar madeirense y de esclavos. Así, se ha podido conocer algunos aspectos de la actividad y la vida de varios portugueses dedicados a la venta de esclavos en el mercado mallorquín.

Una mayoría de los súbditos portugueses que llegaron a la isla eran hombres, lo hicieron solos y estando solteros, pues no se ha registrado a grupos familiares integrados por varios hermanos o padres e hijos que se asentaran en Mallorca simultáneamente. Tras llegar a la ciudad, muchos de ellos casaron con mujeres insulares y tuvieron descendencia, lo que les permitía crear una red de solidaridad familiar basada en el parentesco por afinidad, que facilitaba su integración en la sociedad mallorquina y les 
socorría en los momentos de necesidad. Asimismo, algunas noticias proporcionadas por los protocolos permiten intuir una cierta colaboración entre los lusos afincados en la ciudad, pues fue habitual que se eligieran como procuradores, o que actuasen como testigos en los documentos de sus conterráneos.

A pesar de la diversidad de casos estudiados, se puede afirmar que su condición social no fue destacada, formaron parte de los grupos populares, pues no se ha registrado a ningún alto burgués, ni siquiera a un maestro artesano que tuviera taller propio en la ciudad. Asimismo, las cantidades de las dotes aportadas por sus esposas, y los bienes que declaran en sus testamentos, no son especialmente abundantes: están en consonancia con las habituales entre los menestrales, o de los escuderos de donceles, a excepción del testamento de Damiana Climent, esposa de Juan Martín, que denota un cierto poder adquisitivo, obtenido, posiblemente, en el comercio de esclavos. La muerte de los hombres portugueses provocó la depauperación de sus viudas y huérfanos, que en numerosas ocasiones tuvieron que dedicarse al servicio doméstico, integrarse en alguno de los talleres de la ciudad, o tuvieron que ser ayudados por su familia materna para cubrir sus necesidades básicas.

Pero esta breve mirada también ha permitido observar cómo los lusos hostigaron a los principales mercaderes mallorquines, que sufrieron numerosos ataques piráticos mientras se aproximaban a la isla, como el acontecido en 1472. La resolución por parte del rey del conflicto surgido por el ataque sufrido por Jordi Sureda es poco habitual en tiempos de paz con Alfonso V de Portugal. Sin embargo, se explica por la necesidad económica que tenía Juan II en ese momento para financiar la guerra civil.

Piratas, peregrinos, mercaderes, marinos, calafates, zapateros, birreteros, tintoreros, lapicidas y escuderos portugueses son los protagonistas de estas páginas que han permitido hacer una primera aproximación a su trayectoria vital y actividad en la isla de Mallorca en los últimos tiempos medievales. Son una pequeña contribución al estudio de la presencia y actividad de los lusitanos en el archipiélago balear pero, sin duda, éste es aún un campo abierto en el que profundizar.

\section{Bibliografía citada}

Abufalia, David. Un emporio mediterráneo. El reino catalán de Mallorca, Omega, Eds, Barcelona, 1994.

Abulafía, David, El gran mar. Historia humana del Mediterráneo, Crítica, Barcelona, 2013.

Airaldi, Gabriella, "Portoghesi tra tre mari”, Cusati, María Luisa, (Coord.), Atti congresso internazionale "Portogallo e il mare: Un incontro tra culture" Napoli 15-17 diciembre 1994, Instituto Orientale, Napoli, 1997, vol I, pp.110-117.

Barceló Crespí, María, "Problemàtica del Gremi de Tintorers devers 1487", IX Jornades d'Estudis Històrics Locals: La manufactura urbana i els menestrals (Segles XIII-XVI), IEB, Palma, 1991, pp. 223- 234. 
Barceló Crespí, María, El Raval de la mar de la ciutat de Mallorca, Segles XIII-XV. Lleonard Muntaner, Palma, 2012.

Barceló Crespí, María; Ferrer Vidal, María Antonia, "El servicio doméstico femenino en la Mallorca Bajomedieval", en Ramos, María Dolores; Vera, Teresa, (Eds.). El trabajo de las mujeres. Pasado y presente, CEDMA, uma, Málaga, 1996, Vol.I, pp.207-221. Barceló Crespí, María; Rosselló Bordoy, Guillem, La ciudad de Mallorca. Vida cotidiana en una ciudad mediterránea medieval, Lleonard Muntaner, Palma, 2006.

Bernat i RocA, Margalida, Els “III mesters de la llana”: Paraires, Teixidors de Llana i Tintorers a Ciutat de Mallorca (Segles XIV-XVII), IEB, Palma, 1994.

Bernat i Roca, Margalida, "De la companyia al monopoli: El cas dels tints (S. XV)", Afers, IX, 18, 1994, pp. 443-460.

Cateura Bennàsser, Pau, "El consulado medieval de Castilla en el Reino de Mallorca", Actas del II Congreso de Historia de Andalucía, Vol. 2, 1994, pp. 289-298.

D'ARIEnzo, Luisa, "Veneziani in Portogallo e portoghesi a Venezia nell'Età delle scoperte", Actas do congreso Internacional Bertomeu Dias e a sua época, Porto 1988, vol. 3.pp. 427-443.

Duarte, Luis Miguel, "Regresso a Ceuta" en Fonseca, Luis Adão da; CAdeddu, María Eugenia, (Coords), Portogallo Mediterráneo, ed. Consiglio nazionale delle ricerche, Istituto sui raporti italo-iberici, Cagliari, 2001, pp. 99-142.

DuARTe, Luis Miguel, Ceuta 1415. Seisentos anos depois. Livros Horizonte, Lisboa, 2015. DufourQ, Charles-Emmanuele, "Aspects internationaux de Majorque durant les derniers siècles du Moyen Âge", Revista Mayurqa, no 11, 1974, pp. 5- 52.

FÁBregas GarcíA, Adela, “Actividad marítima y mercantil nazarí en el Magreb occidental: relatos de un observador portugués en el Estrecho", Revista del Centro de Estudios Históricos de Granada y su Reino 20, 2000, pp. 151-173.

Ferrer Mallol, María Teresa, "Productes del comerç catalano-portuguès segons una reclamació per piratería (1408)” Miscel.lània de Textos Medievals, 6, 1992, pp. 137- 163.

Ferrer Mallol, María Teresa, "De nuevo sobre el consulado de castellanos en Cataluña y Mallorca a finales del siglo XIV", en Poder y sociedad en la Baja Edad Media Hispánica. Estudios en homenaje al profesor Luis Vicente Díaz Martín, Universidad de Valladolid, 2002, II, pp. 951-969.

FonseCA, Luis Adão da, Navegación y Corso en el Mediterráneo Occcidental. Los portugueses a mediados del siglo XV. Eunsa, Pamplona, 1978.

FonseCA, Luis Adão da, “O porto nas rotas de Mediterrâneo Occidental (vésperas da Época Moderna), Revista de História”, III, 1982, pp. 127-139.

FonsECA, Luis Adão da, “As rotas da navegação portuguesa entre o Mediterrâneo e o Atlântico na época de Colombo" en Navi e navigazione nel secoli XV e XVI, V Convegno Internazionale di Studi Colombiani, Génova 1990, vol II, pp. 517-535.

Fonseca, Luis Adão da, Portugal entre dos mares. Mapfre, ed. Madrid 1993. 
FonseCA, Luis Adão da, "Portugal e o Mediterrâneo no final da Idade Média: uma visião de conjunto", en FonsecA, Luis Adão da; CAdeddu, María Eugenia, (Coords), Portogallo Mediterráneo, ed. Consiglio nazionale delle ricerche, Istituto sui raporti italo-iberici, Cagliari, 2001, pp. 13-27, p. 17.

Fonseca, Luis Adão da; CAdeddu, María Eugenia, (Coords), Portogallo Mediterráneo, ed. Consiglio nazionale delle ricerche, Istituto sui raporti italo-iberici, Cagliari, 2001.

FonsecA, Luis Adão da, "Le Portugal et la Mediterranée au XVe siècle", Archivos do Centro cultural Calouste Gulbenkian, Vol XLIII, Le Portugal et la Mediterranée, Lisboa, 2002, pp. 3-34.

Giral-HardziIossif, Jacqueline, Valence, port méditerranéen au XVe siécle, (1410-1525), Piremes, París, 1985.

González ArÉvalo, Raúl, "Portugal y el comercio de esclavos en Málaga a fines de la Edad Media", La Península Ibérica entre el Mediterráneo y el Atlántico. Siglos XIII$X V$, GonzÁlez Jiménez, Manuel, (coord.), SEEM, Sevilla-Cádiz, 2006, pp. 103-109.

GonZÁlez ArÉvalo, Raúl, “Acordes y desacuerdos. Navegación y comercio de las galeras mercantiles de Venecia y Florencia en el Mediterráneo ibérico desde una perspectiva comparada", GonZÁlez ArÉvAlo, Raúl, (Coord), Navegación institucional y navegación privada en el Mediterráneo medieval, Alhulia, 2016, pp. 156-157.

Gourdin, Philippe, "Présence portugueise en Méditerranée occidentale et au Magreb au XVeme, siècle”, en Luis Adão da Fonseca y María Eugenia, CAdeddu, (Coords.), Portogallo mediterraneo, pp.130-142.

HeErs, Jacques, "L'expansion matitime portugaise à la fin du Moyen Age. La Mediterranée", Revista de Faculdade de Letras de Lisboa, Tomo XXII, $2^{\mathrm{a}}$ série, no 2, 1956, pp. 5-33. HeErs, Jacques, "Portugais et Génois au XVe Siècle: La rivalité Atlantique- Méditerranée”, Actas del III Coloquio Internacional de Estudios Luso-brasileiros, Lisboa 1960, vol. II, pp. 138-147.

Hinojosa Montalvo, José, "De Valencia a Portugal y Flandes. Relaciones durante la Edad Media", Spr. Anales de la Universidad de Alicante, Historia Medieval, 1, 1982, pp.149-168. Hinojosa Montalvo, José, "La piratería y el corso en las costas alicantinas durante la Baja Edad Media", VIII Jornades d'Estudis Histórics Locals. El comerç añternatiu. Corsarisme i contraban (ss. XVI-XVIII), IEB, Palma, 1991, pp. 55-69

Houssaye- Mchienzi, Ingrid, Datini, Majorque et le Maghreb (XIV -XV siècles). Réseaux, espaces, méditerranées, et stratégies marchandes, Brill, Leinden/Boston, 2013.

Houssaye- MichiEnzi, Ingrid, “Entre Majorque et l'Afrique: configuration de l'espace réseaux juifs d'après les sources comerciales italiannes (fin XIV ${ }^{\mathrm{e}}$ - debut XV $\mathrm{X}^{\mathrm{e}}$ siècle)", Revue des études jueves, 173, (1-2), 2014, pp. 139-174.

Iradiel, Paulino; Igual, David, "Del Mediterráneo al Atlántico. Mercaderes, productos y empresas italianas entre Valencia y Portugal, (1450-1520)", FonsECA, Luis Adão da; Cadeddu, María Eugenia, (coords.), Portogallo mediterraneo, pp. 143-194. 
JuAn Vicens, Antonia, "El Estatus social del artesano de la piedra a finales de la Edad Media”, Medievalismo, 23, 2013, pp. 241-264.

JuAn Vicens, Antonia, Lapiscida vel ymaginarius. L'art de la pedra a la baixa Edat Mitjana, Publicacions Abadia de Montserrat, 2014.

JUAN VICENS, Antonia, "El arquitecto y escultor Joan Oliver y otros lapiscidae sicilianos activos en Mallorca durante la Baja Edad Media”, Lexicon 18, 2014, pp. 7-16.

López Beltrán, María Teresa; GonzÁlez Arévalo, Raúl, "Portugueses en el Reino de Granada en época de los Reyes Católicos (Málaga, 1487- 1518)", Baetica. Estudios de Arte, Geografía e Historia, 24, 2002, pp. 309- 338.

López de Coca CASTAÑer, José Enrique, "Granada y la expansión portuguesa en el Magreb extremo”, Historia. Instituciones. Documentos 25, 1998, pp. 351-367.

López de Coca Castañer, José Enrique, "Las galeras venecianas de Poniente y Berbería desde la perspectiva española" Medievalismo 16, 2006, pp. 113- 172.

LóPEz PÉrez, María Dolores, La Corona de Aragón y el Magreb, CSIC, Barcelona, 1995. MACAIRE, Pierre, Majorque et le commerce international, (1400-1450 environ), atelier de reproduction de these, Université de la Sorbonne, Paris, 1983, pp. 486-487.

Madurell Marimon, Josep María, "Portugueses em Barcelona (1391-1441)”, Bracara Augusta, XVI/XVII, 1964, pp. 254-279.

Mas Forners, Antoni, Esclaus i catalans. Esclavitud i segregació a Mallorca durant els segles XIV $i$ XV, Lleonard Muntaner, Palma, 2005.

MAs Forners, Antoni, "La incidencia del mercado de esclavos en la estructura productiva de Mallorca (aprox. 1300-1450)", en Plazolles Guillén, Fabienne; Travelsi, Salah, (coords.), Les esclavages en Méditérranée, espaces et dynamiques économiques, Casa de Velázquez, 2012, pp. 77-100.

Miranda, Flávio; FAria, Diogo, "Lisboa e o comerço marítimo com a Europa nos séculos XIV e XV", João Luis IngLÊs Fontes, et Alii (Coords), Lisboa Medieval. Gentes, espaços e poderes, IEM, Lisboa, 2016.pp. 241-266.

Muñoz Pomer, María Rosa, y Navarro Espinach, Germán, "Los mercaderes y la fiscalidad: el dret dels portuguesos en Valencia (1464-1512)”, FonsecA, Luis Adão da; María Eugenia, CAdeddu, (coords.), Portogallo mediterraneo, 2002, pp. 195-257.

Muñoz Pomer, María Rosa, Navarro EsPinach, Germán; IGUAL, David, "El comercio de importación portugués en Valencia, 1487-1488”, Os reinos ibéricos na Idade Media. Livro de Homenagem ao Professor Doutor Humberto Carlos Baquero, FonseCA, Luis Adão da, Amaral, Luis Carlos, Libraría Civilização, Porto, 2003, vol. 3, pp. 1121-1133.

Muñoz Pomer, María Rosa, "El eco de Portugal y los portugueses en Valencia (ss. XIV-XVI), Estudos en Homenahem ao Professor Doutor José Marques, Universidade do Porto, Porto, 2006, vol 4, pp. 61-84.

Muñoz Pomer, María Rosa, Navarro Espinach, Germán; IGUAL, David, "El comercio portugués en el Mediterráneo occidental durante la Baja Edad Media”, La Península 
Ibérica entre el Mediterráneo y el Atlántico. Siglos XIII-XV, GonZÁLEZ JimÉneZ, Manuel, (coord.), SEEM, Sevilla-Cádiz, 2006, pp. 73-84.

Ortega Villoslada, Antonio, El reino de Mallorca y el mundo Atlántico. Evolución política y mercantil. Uned, 2008.

Ortega Villoslada, Antonio, "Dinis, Sancho I de Mallorca y Juan XXII: artífices del intercambio mercante Mallorca-Portugal", en A guerra e a sociedade na Idade Média. VI Jornadas Luso-Espanholas de Estudos Medievais, Sociedade Portuguesa de Estudos Medievais, Lisboa, 2008, Vol II, pp. 61-68.

Ortega Villoslada, Antonio,"Ciudadanos atlánticos en Mallorca (1230-1349)", El Regne de Mallorca: crüilla de gents i de cultures (segles XIII-XV), Jornades d'Estudis Histórics Locals, Palma, 2008, pp. 347- 359.

Ortega Villoslada, Antonio,"Oporto y Mallorca en la primera mitad del siglo XIV", http://www.citcem.org/encontro/pdf/new_02/TEXTO\%20\%20Antonio\%20Ortega\%20 Villoslada.pdf, [Consultado 10/09/2018]

RAU, Virginia, "Portugal e o Mediterrâneo no século XV. Algunos aspectos diplomáticos das relações com a Itália". Centro de Estudos da Marina, Lisboa, 1973.

Roselló Lliteras, Joan, Registra Sponsalium ecclesie Maioricensis "Consenssos", Palma 1981, vol III, (1460- 1461, 1496-1497).

Rosselló Vaquer, Ramón; Bover Pujol, Jaume, "El sexe a Mallorca". Notes històriques, III, 1996, Palma.

Rosselló Vaquer, Ramón, Noticiari de Felanitx, 1228-1599, Felanitx, 1997.

SANTAMARÍA, Álvaro, "La formación profesional en Mallorca en la época de Fernando el Católico", Príncipe de Viana. Anejo, no 2-3. 1986, pp. 651- 668.

SASTRE MolL, Jaume, "La actividad comercial del mercader mallorquín Johan Barthomeu a mediados del siglo XV", Mayurca, 31, 2006, pp. 251-273.

SAStre Moll, Jaume, La dona medieval a la ciutat de Mallorca (ss.XIII-XV), LLeonard Muntaner, Palma, 2017.

Sevillano Colom, Francisco, "De Venecia a Flandes, (vía Mallorca y Portugal)", BSAL, 33, 1968, pp. 1-33.

Sevillano Colom, Francisco, Mercaderes y navegantes mallorquines, Historia de Mallorca, Palma, 1970.

SzÁszdi LeÓn-BorJa, István, "Sobre el consulado castellano en Mallorca en la Baja Edad Media", Anales de la Universidad de Alicante. Historia Medieval. 10, 1994-1995, pp. 215-232.

Themudo Barata, Filipe, Navegação comércio e relações políticas: os portugueses no Mediterrâneo ocidental. Fundação Calouste Gulbenkian, Lisboa, 1998.

Unal, Anna, Ceuta 1415.Los orígenes de la expansión europea en África. Archivo Central, Ceuta, 2004. 
VAquer BennÀssar, Onofre, "El contrato de trabajo en la Mallorca medieval. Aprendices, criados y obreros en el siglo XV", Homenatge a Álvaro de Santamaría, vol II, Mayurca, 22, 1989, pp. 645-654, p. 647.

VAQUER BenNÀSAR, Onofre, "Inmigrants a Mallorca a la segona meitat del segle XV", BSAL, 51, 1995, pp. 125-140.

Vaquer Bennàssar, Onofre, L'esclavitud a Mallorca. 1448-1500, Institut d'Estudis baleàrics, Consell Insular de Mallorca, Palma, 1997.

Vaquer Bennàsar, Onofre, El comerç maritim de Mallorca, 1448- 1531, El Tall, Palma, 2001.

Vaquer Bennàsar, Onofre, Concessos segle XV, http://www.llinatgesdemallorca.com/ category/segle-xv/concessos/ [Consultado 18/09/2018] 
